\title{
HELGA NOWOTNY
}

\section{Dare to know, dare to tell, dare to play}

$\mathrm{n}$ her concluding statement summarising the discussions and themes presented during the workshops, lectures and concerts of the Aboagora symposium, Helga Nowotny underlines the need for researchers to be courageous and creative as they rethink the Enlightenment heritage in their various fields of research. Researchers today are part of an enormous epochal transformation in science, technology and institution building, she claims. This is a world largely of our own making which provides new opportunities as well as challenges and in which the future cannot be known. Yet, Nowotny points out, we continue with the desire to influence the future and we try to prepare for the encounter with a messy world of enormous complexity, uncertainty and contingency around us. In this situation, she concludes, music can provide science with an important lesson, namely: it is played. Playfulness can provide one possible mode to prepare for the future: by playing one learns to explore and to trust one's own curiosity. Thus, the Enlightenment is unfinished, but it is also exciting in being unfinished.

My SUMMING UP OF THE ABOAgORA conference will consist of three sections. In the first part I will take us through what I think we have tried to achieve. The second part, admittedly based on a very subjective and therefore selective reading, will focus on some of the most interesting questions that were raised in these past few days. Finally, in the third part, I would like to give all of us something to think about when we no longer are here in Turku, namely: what will follow on from these days that we have spent together?

\section{I}

What we have tried to achieve can easily be summarised: we've attempted to contextualise the Enlightenment. Contextualisation is a process that is not taught in many places and yet it is crucially important. Whenever we encounter ideas, when we study social or intellectual movements, or the transmission of ideas throughout history we must ask ourselves: where do these ideas come from? How did they emerge and how did they acquire their power? What are their limitations? This is what we have tried to do. In rethinking the Enlightenment we have to contextualise it. We started with Yehuda Elkana's opening remarks on rethinking the Enlightenment, for which we are very much indebted, and from there we made our way through the many, multi-layered meanings that the Enlightenment has gathered to itself over time and space. We have been exposed to ideas of the Enlightenment in many different ways and contexts and the crucial question remains: how can we contextualise these different, even contradictory interpretations?

In the history of ideas in the West, traditional trajectories usually go back to highly esteemed points of reference, such as Plato, Aristotle or other great thinkers, following their ideas and those of their successors through the ups and downs of history. Interestingly enough, what one discovers on such journeys is that thinkers often had to rebel against their predecessors, what they had thought, said, taught and what they fought to disseminate. If we want to understand how the tradition of Western thinking evolved, we must therefore pose the question: what was this thinker against, not just what was the thinker for. We must try to conceptualise and contextualise the background against which these thinkers were working, to see what their ideas have meant in their own time and how they have subsequently been transformed over the course of history. This also holds true for the Enlightenment; what we make of it today and what remains of it to this day.

We also spoke about the Enlightenment as a 
movement-a political and social movement, as well as a movement of ideas. It became clear that not only were great minds involved, but many other minds as well. We know the names of some of the people involved from historical archives, but in many cases they remain nameless. Yet, we know about the existence of many different social groupings, often dispersed and in faraway places; there were teachers, notaries and medical people who were eager to absorb Enlightenment ideas and were adamant to feed them into their daily practices and their aspirations for a better future. Their engagement with Enlightenment ideas was based on the firm belief that a systematic inquiry into the natural world and the pragmatic application of the understanding thus gained, would lead to a vast improvement of life and of society. Humanity was no longer bound by fate, but had acquired agency.

Therefore, I would like to emphasise that social connectivity always exists, closely connected to the world of ideas. For the purposes of analysis one can always abstract ideas and lift them out of their context. But at the same time we should not forget: ideas are embedded in many different kinds of social connectivity; they take different forms in various kinds of social communities, in organisations and in what today we would call networks. Something also strongly emphasised by many workshop participants was: what were the particular strategies in knowledge production and creation; what made Enlightenment thinking different from what had preceded or followed it? And how were these strategies of knowledge production, and not only their results, distributed throughout Europe?

Contextualisation obviously also implies bringing back the historical dimension, and we started with Jean-Louis Fabiani emphasising the importance of localities: not just who, but of places-where? In the eighteenth and in subsequent centuries, this inevitably meant also national, even nationalistic, contexts. This is an integral part of our common European history; there is no way of escaping it. It is the history of the rise of the nation states, which includes the enormous human suffering brought about by wars as the darkest of the many dark sides of the process of nation-building and expansion. But, as we were also reminded in the discussions led by the Finnish researchers and students: even within the various national contexts there was always a non-national, European dimension present, as many of those involved in discussing and practising Enlightenment ideas came from different countries. So, when we speak of the French, or the Scottish, or the Finnish Enlightenment, those who actively contributed came not only from France, Scotland or Finland. An underlying current in the exchange of ideas always existed. In this sense, contextualising the Enlightenment results in appreciating that it was much more European, avant la lettre, than we sometimes tend to think.

Then, of course, we debated and tried to contextualise the broad question of its reception. The reception of ideas is always selective; we keep on rewriting history-this is what historians do, they rewrite history all the time because they find new sources and/or a new perspective. The reception of ideas also depends on the context of time and place, on other ideas that are already there. Contextualisation, lastly, also means asking the question: what remains today? What meaning, what sense, do we make of what remains?

I will not even attempt to answer this question. But we got at least some very valuable hints of what went wrong: the cracks that appeared in the Enlightenment even early on; its false notion of universalism-the French thought they had bestowed a gift on the world by exporting their version of universalism together with the Enlightenment-and other notions that became marginalised, side-stepped or forgotten. Fabiani was talking about the public versus the clandestine; others about the radical versus the mainstream and I would like to mention again the split that occurred between reason, reasonableness and sentiment. Les sciences morales seemed a feasible aspiration at the beginning of the Enlightenment, very much part of it. The hope was that the so-called scientific method, which demonstrated that it was possible for scientists to reach a consensus and to be in some kind of agreement on what they were talking about and how they were exploring and explaining nature, would permit them to implement a similar procedure also in the political sphere, disrupted as it was by political and civic strife, and continuous wars between nations. This is one of the high hopes that did not materialise. People realised this very early on and that is why, up to this very day, we have a split between the notion of progress or advancement that is related to the scientific, technological civilisation in which we live and a deplorable lack of progress in the political, social and moral aspects of society. We have not really been able to take this very much further here, but the issue will not go away.

The subversive power of the Enlightenment, emphasised by several speakers, was something that resonated strongly in me. This subversive power was 
manifest from the very beginning in the Enlightenment in terms of speaking out against the authorities of the day: the authorities of the church and state, who, by being authorities, had the right to pronounce which knowledge was right and which knowledge was wrong, what is and what is not knowledge. The subversive power of the Enlightenment undermined this authority, emphasising scepticism and doubt, while seeking to empower the individual, as we would say in today's language. So, to summarise the first section of my concluding statement: in contextualisation we must always become aware of our present context. We cannot contextualise while taking a view from nowhere, or while attempting to take a stand outside of where we are positioned now. Contextualisation means to relate what we are contextualising to the context in which we are embedded; it actually means: dare to know - in context.

We have also heard more subtle undertones, such as questions about fear, anxiety and uncertainty. The counterpart of such a discourse is the yearning for some kind of recognisable, even unambiguous message, for a certainty that allows us to combat these fears and anxieties while daring to be open to admit and to analyse the context of which we are a part. This is yet another example of the contradictions in beliefs and values that surfaced again and again; contradictions that we were exhorted to embrace. Living with contradictions and coping with uncertainties are included in the practices of contextualisation that I am talking about.

\section{II}

My second section deals with the questions that,my apologies - were of greatest interest to me personally, but I hope you will agree with me in this evaluation. A question that provided the red thread in many of our discussions was: What can science, art, language-and to some extent religion-as well as the everyday experiences of ordinary people tell $u s$ ? This question emerged repeatedly leading to a subsequent question: what can science, art, language not tell us? We cannot only speak about what science or language or art can tell us without posing the question as to what each of them cannot tell us.

I find this question interesting because it arises in the midst of a contemporary situation which is thoroughly infused by the desire to communicate. I would say, furthermore, that Finland is a good place for this. Many of us have Nokia phones and Finland has made impressive strides in pioneering commu- nication and information technology; this is part of the economic basis of this country, which you all have a right to be proud of. The more we are surrounded by these new information and communication technologies, the more pressing becomes the desire to communicate as does the question of how to communicate, that is to say, how to connect with others through technological means, but also beyond technological means. What kinds of communication forms can we establish with other communities that we would perhaps not have reached without them? It also reshapes the links to the communities into which we were born, in which we grew up and which we are familiar with, as well as to emergent and newlyformed, perhaps more ephemeral communities.

Over the last few days we have repeatedly accessed the world of tales, narratives, stories and languagethe different kinds of languages used in science and in the arts- which I find quite remarkable. To what extent can we use such tales, different narratives and stories to communicate? I think this is one of the underlying common and desirable aspirations that motivated and fuelled many of the debates.

This may be one of the reasons why Dan Sperber's work is so pertinent and important. He emphasises that people do not just imitate and mechanically repeat ideas, but rather engage in creative reproduction in various causal chains. Sperber also links what happens in the individual within the surrounding context: we all perceive ideas, but none of us perceives ideas that do not also touch the public sphere. This continuous interlinking with the public spherewhat others think, discuss and communicate and how this feeds back to us as individuals, to be emitted again and transformed-charts a map for a feasible and productive research agenda that would need to be filled with empirical data from many different fields. We were presented with just such a potentially rewarding conceptual tool, to be taken away with us for further creative use.

This also holds for what François Taddeï and Ariel Lindner, in the session I chaired, illustrated as being part of an ongoing process of the co-construction of science and society, referring to what scientists do and how we can involve the public. Such involvement proceeds by telling tales, by communicating in novel ways and by inventing, for instance, scientific discovery games as a new way to engage the public. And as to the how of telling a story, we all can learn from what linguists call 'code switching', that is, the ability to switch back and forth between languages in a conversation without interruption or conscious effort. 


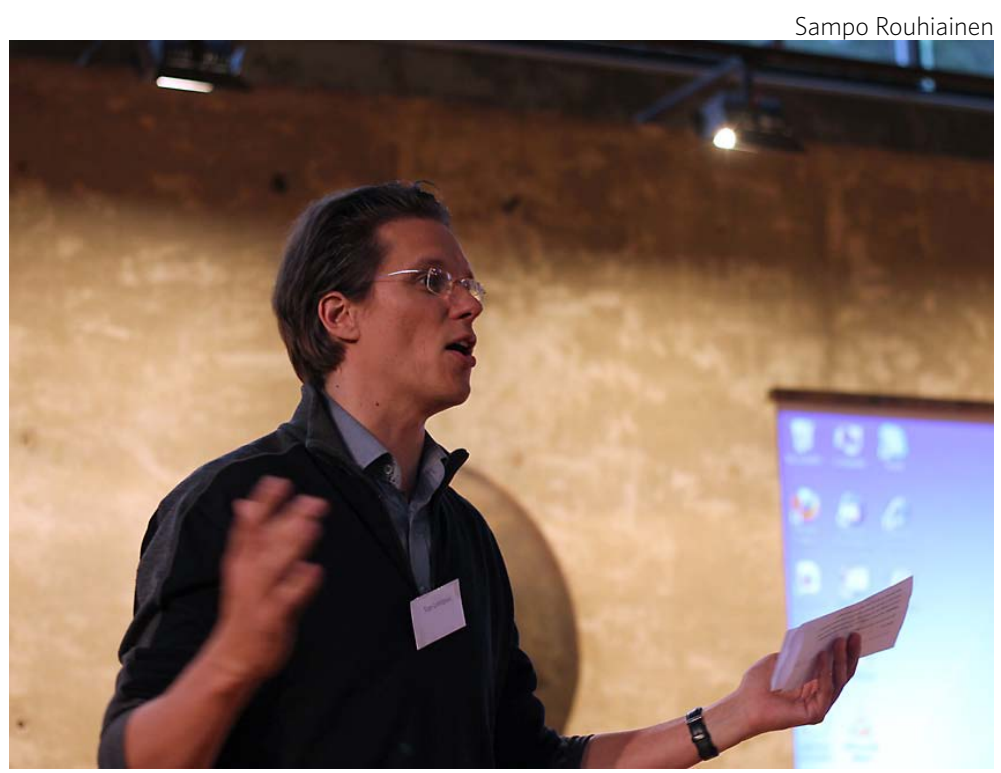

The artistic director of Turku Music Festival, tenor Topi Lehtipuu, speaking at Aboagora. Lehtipuu is one of the driving forces in the organising committee of Aboagora, enthusiastically building bridges between the art world and academia.

This, of course, presupposes that you are thoroughly familiar with more than one language and that there is a space inviting the intermixing and intermingling. We have talked about zooming and scaling - all these are ways and approaches to how one can try to answer the question of what science, art, language and music can tell us, how far this can take us and what lies beyond.

Now, communication may be functioning at a basic level, but it needs social links that are embedded in a particular space, time and social setting, as we all know from everyday personal experience: in a certain atmosphere and setting one feels at much greater ease to talk to others, while other settings constrain, restrain or formalise. Technology, of course, is one of the most important continuing innovations in this respect, but it needs social spaces that have to be cultivated. This is where the notion of 'culture' comes in. How can we cultivate spaces of communication and education, of borderlands to cross and to render them fertile? And finally, speaking of cultivation and culture: what are the new challenges and possibilities offered by the planet earth in the era of globalisation? Not all is gloomy and prone to disaster, and we should be more realistic in becoming aware of the intellectual and scientific resources at our disposal.

Hence, all these multiple, interlinked spaces of private and public, of local and global, of North and South, are dependent on communication; that is, on telling stories. Indeed, it is a human characteristic to tell stories. So, to the Kantian 'dare to know', reformulated as 'dare to know in context', I would like to add 'dare to tell.' Dare to tell stories, dare to switch the media in which you speak, in which you communicate-be it science or art or some other medium. Dare to use them all and dare to experiment in doing so, for they all are part of our human endowment to communicate with each other.

\section{III}

What follows on from this? What follows is that we also have to look at the cracks that have appeared in edifice of the Enlightenment; we have to look at its melancholic side as well. As Yehuda Elkana reminded us, not all is sweetness in melancholy, as it is an expression of an unfulfilled yearning. Let us analyse in greater depth that part of the Enlightenment that intended to be subversive but did not succeed. There are instances where the Empire struck back and thus suppressed its subversion. There may have been other factors that caused noble intentions to fail. We know the dark sides, they certainly exist and we spoke about them. The in-between spaces may be comforting, but there are also in-between spaces that are rather discomforting zones in which misunderstandings thrive and which, far from being productive, can become devastatingly destructive.

So what can be done, what is to be done? I would like to re-emphasise what I said initially in my session: we have to realise and accept that the world in which we live is largely a world of our own making. We are active agents in this enormous epochal transformation that we are currently living through-science and technology are the most obvious contributors, but the transformation takes place at different levels, each with their own complexity, contingency and uncertainty; it includes institutions, or rather the lack of adequate institutions, because there is a gap in institution building which renders us unfit and unprepared for an immensely fragile future.

This world, largely of our own making, provides new opportunities and spaces that exhilarate and expand and provide utopian and not-so-utopian spaces: for instance for education on a global scale. In every utopia one chapter is devoted to education because it continues to be the window towards the future by 
means of the intergenerational transmission of learning. In a utopia, furthermore, the projection into the future is done in a subtle way; utopias do not tell us how to get there, they only paint a picture of what is desirable, but leave it to us to figure out how to get there. This is what I mean by not-so-utopian spaces: it is hard work to figure out how to get from where we are to where we would like to be. Definitely, education must be approached in a non-utopian mode.

The future cannot be known. Therefore: distrust any predictions that attempt to convince you otherwise, for you can be pretty sure that the future will be different from what has been predicted. A world of things and ideas consists not only of ideas and things, but is made of the connections between ideas, things and human agents, of the mediation of ideas through things, through the medium used that amplifies and reinforces or splits things, ideas and people in novel ways. And yet, we continue to wish to influence the future, we want to have an impact and shape it. This means to prepare ourselves in ways that are not learned from our previous ways of doing and thinking; to prepare for this very messy world of enormous complexity, uncertainty and contingency. Preparedness for what we are not prepared for is therefore the real challenge ahead.

In this situation, music, this wonderful universe of music into which we have been immersed and that has been one of the highlights of these past few days, can teach us something. Namely: it is about play. The notion of playing and playfulness and the curiositydriven games of discovery provide one possible mode in which to prepare for what you cannot really prepare yourself for. Learning to play and to explore, learning to trust one's own curiosity-and curiosity never knows where it will lead-is my third conclusion. All we have, which is little and much at the same time, is personal and collective experience; the everchanging links between past and present and the feedback they provide. Therefore: dare to play.

To conclude then, the Enlightenment project is unfinished, but it is still exciting in being unfinished. It is up to us to take what we find to be most valuable from the Enlightenment's legacy and to reshape it, reformulate and rethink it, reinvent it even, in order to take ideas and institutions forward to a future that is unknown: dare to know, dare to tell, dare to play.

Concluding statement of Aboagora, presented on 18 August 2011. Transcribed by Ruth Illman, edited by Helga Nowotny.

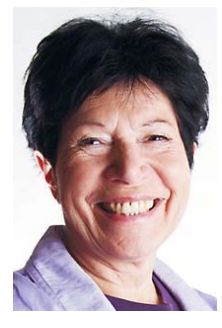

Helga Nowotny is Professor emerita of Social Studies of Science, ETH Zurich (Swiss Federal Institute of Technology) and a founding member and President of the European Research Council (ERC). She holds a PhD in sociology from Columbia University (NY) and a doctorate in jurisprudence from the University of Vienna. Her current host institution is the Vienna Science and Technology Fund (WWTF). Helga Nowotny is Chair of the Scientific Advisory Board of the University of Vienna and member of many other international Advisory Boards and selection committees. She is a foreign member of the Royal Swedish Academy of Sciences and long standing member the Academia Europaea. Helga Nowotny has published more than 300 articles in scientific journals. Her latest book publications include Naked Genes: Reinventing the Human in the Molecular Age (with Giuseppe Testa, MIT Press 2011), Insatiable Curiosity: Innovation in a Fragile Future (MIT Press 2008) and Cultures of Technology and the Quest for Innovation (ed.) (New York \& London 2006). She is also a member of the advisory board of Aboagora. E-mail: helga.nowotny(at)wwtf.at. 